\begin{tabular}{ccc} 
Tersedia online di: http://ejournal-balitbang.kkp.go.id/index.php/jppi & JURNAL \\
e-mail:jppi.puslitbangkan@gmail.com & PENELITIAN \\
PERIKANAN & INDONESIA \\
JURNAL PENELITIANPERIKANANINDONESIA & Volume 24 Nomor 1 Maret 2018 \\
p-ISSN: 0853-5884 & e-ISSN: 2502-6542 \\
Nomor Akreditasi: 653/AU3/P2MI-LIPI/07/2015 & \\
\hline
\end{tabular}

\title{
SEBARAN, POTENSI INTRODUKSI, DAN PENGENDALIAN IKAN BERBAHAYA/INVASIF DAN BERPOTENSI INVASIF DI YOGYAKARTA DAN SEKITARNYA
}

\section{HARMFUL/INVASIVE AND POTENTIALLY INVASIVE FISHES IN YOGYAKARTA AND SURROUNDINGS: SPREAD, INTRODUCTION POTENTIALS AND CONTROL MEASURES}

\author{
Himawan Achmad*1, Laili Martini', Sutopo Aris Wibowo', dan Lantip Nugroho' \\ ${ }^{1}$ Stasiun Karantina Ikan Pengendalian Mutu dan Keamanan Hasil Perikanan Kelas I Yogyakarta \\ Jl. Kenanga No. 26 Maguwoharjo, Depok, Sleman, Yogyakarta, kode pos 55282, Telp/fax: (0274) \\ 489390, email: ski2 jogja@yahoo.com \\ Teregistrasi I tanggal: 16 Nopember 2017; Diterima setelah perbaikan tanggal: 29 Januari 2018;
} Disetujui terbit tanggal: 20 Februari 2018

\begin{abstract}
ABSTRAK
Pengendalian penyebaran ikan berbahaya, invasif dan berpotensi invasif di Indonesia terutama bertumpu pada pelarangan lalu lintas ikan pada pintu pemasukan dan pengeluaran, sedangkan kesadaran dan peran serta masyarakat masih rendah. Di lain pihak, regulasi yang mengatur lalu lintas ikan tersebut minim dan upaya penegakan hukum terhadap perdagangan dan budidayanya belum maksimal. Akibatnya 78 jenis ikan berbahaya dari total 152 yang dilarang masuk ke Indonesia tersebar di pusat perdagangan ikan hias dan perairan umum. Sehingga edukasi kepada publik perlu ditingkatkan sejalan dengan perbaikan regulasi melalui pemetaan sebarannya sebagaimana dilakukan dalam studi ini. Survei dilakukan di Yogyakarta dan sekitarnya untuk menginventarisir penyebaran spesies target di lokasi perdagangan ikan hias dan mendapatkan gambaran persepsi responden terhadap pelepasliaran. Penelitian ini menemukan bahwa peran manusia signifikan dalam introduksi ikan asing pada habitat baru, tercermin dari propagule pressure, yang dianalisa dengan statistika bayesian, pada 8 dari total 29 spesies target mencapai lebih dari 100 individu. Ditemukan Atractosteus spatula, Pygocentrus nattereri, dan Arapaima gigas yang berbahaya bagi manusia, diperdagangkan dengan persentase sebaran masing-masing $41 \%, 30 \%$, dan $13 \%$. Analisa varian dua arah menunjukkan responden yang berlokasi mandiri menyediakan lebih banyak jenis ikan target $(p<0,05)$. Survei untuk menggali pengetahuan, kesadaran, dan tanggungjawab responden menunjukkan bahwa dari 8 pertanyaan yang diajukan hanya $25 \%$ yang mendapat respon positif bagi pencegahan penyebaran spesies target. Dalam jangka panjang, strategi pengendalian penyebaran spesies target harus melibatkan lebih banyak peran masyarakat. Larangan lalu lintas antar wilayah tidak bebas seharusnya dilakukan.
\end{abstract}

Kata Kunci: Berbahaya; invasif; ikan; propagule pressure; pelepasliaran

\begin{abstract}
Control strategy on harmful, invasive and potentially invasive fishes in Indonesia, mainly relies upon restriction of translocation at border despite lack of community awareness and empowerment. However, domestic translocation is lack to regulate and law enforcements on culture and trade of the species are lax leading to presence of around 78 of all 152 prohibited fishes in ornamental fish markets and wild waters. Therefore public awareness should be encouraged while regulations are updated such as that of the mapping conducted in this study. The survey was carried out in Yogyakarta and surrounding areas to know spread of the species among ornamental fish stores and traders, and identifiy respondent's tendency of species release. It revealed that human played significant roles in introducing alien fishes in new habitat, reflected from the propagule pressure analysed by bayesian statistics, that hit more than 100 individuals in each of eight of total 29 species possessing invasiveness. Three species mapped, Atractosteus spatula, Pygocentrus
\end{abstract}


nattereri, and Arapaima gigas, are known harmful for human and traded among 46 respondents with alarming frequencies at $41 \%, 30 \%$ and $13 \%$ respectively. Two ways anova fully factorial revealed that independent stores sold more targeted species $(p<0.05)$. Only $25 \%$ of total eight questions to test knowledge, awareness, and responsibility of respondents were returned with positive perception. Long term control strategy should be underpinned by more public participation. Translocation of inter non-free areas should also be restricted.

\section{Keywords: Harmful; invasive; fishes; propagule pressure; release}

\section{PENDAHULUAN}

Pengendalian penyebaran ikan berbahaya/invasif dan berpotensi invasif di Indonesia saat ini belum dilaksanakan secara optimal akibat minimnya regulasi dan sebarannya belum terpetakan secara komprehensif. Peraturan perundangan-undangan terbaru untuk pencegahan penyebarannya baru berupa Peraturan Menteri Kelautan dan Perikanan RI Nomor 41/PERMEN-KP/ 2014 tentang Larangan Pemasukan Jenis Ikan Berbahaya dari Luar Negeri ke dalam Wilayah Negara Republik Indonesia dengan daftar ikan berbahaya yang harus diperbarui sesuai perkembangan perdagangan yang sangat dinamis. Pengendalian penyebaran spesies target secara lebih tegas misalnya dengan pembatasan budidaya sulit dilakukan. Ikan berpotensi invasif seperti ikan mas (Cyprinus carpio) dan ikan nila (Oreochromis niloticus) (Haryono et al., 2016; Haynes et al., 2012; Zambrano et al., 2006) merupakan target produksi nasional (Dinisari, 2016; DJPB-KKP, 2017). Adapun ikan berpotensi invasif lain seperti ikan bawal (Colossoma macropomum) (Haryono et al., 2016), bernilai ekonomis tinggi di pasar domestik dan luar negeri (Bagjariani, 2013).

Penguatan aspek ilmiah dalam penyusunan peraturan dan kebijakan pengendalian spesies target diperlukan karena persepsi publik termasuk ilmuwan dan penentu kebijakan tidak seragam (García Berthou, 2007; Gozlan, 2008; Gurevitch \& Padilla, 2004; Vitule et al., 2009). Bahkan negara-negara lain seperti Amerika Serikat maupun Brazil menggantungkan produksinya pada kegiatan akuakultur melalui jenis ikan invasif (Naylor et al., 2001; Vitule et al., 2009). Peraturan perundangan-undangan di negara maju pun tidak optimal mencegah peredarannya (Fowler et al., 2007).

Yogyakarta dikenal sebagai sentra produksi benih ikan nasional. Data lalu lintas komoditas ikan Stasiun KIPM Kelas I Yogyakarta menunjukkan seperempat dari rata-rata frekuensi pengiriman ikan dari Yogyakarta merupakan ikan hias, yang mana total volume lalu lintas mencapai lebih dari 100 juta benih pada 2016. Berbagai studi menunjukkan bahwa perdagangan ikan hias merupakan sumber peredaran spesies invasif dan menjadi ancaman signifikan terhadap ekosistem setempat (Ishikawa \& Tachihara,
2014; Padilla \& Williams, 2004). Mengingat pentingnya peran manusia sebagai penyebar spesies target melalui peredaran ikan hias (Chang et al., 2009; Gertzen et al., 2008; Hulme, 2009; Sievers et al., 2012; Turkmen \& Karadal, 2012) maka kajian potensi penyebarannya di Yogyakarta perlu dilakukan. Upaya pencegahan penyebaran mengharuskan identifikasi spesies mana yang beresiko tinggi dan berapa jumlah individu yang berpotensi terlepas secara liar (Kolar, 2004; Kolar \& Lodge, 2001; Ricciardi \& Rasmussen, 1998). Pengkajian potensi terlepasliarnya spesies target juga harus mencakup aspek sosiologis dari aktivitas perdagangan ikan hias yang melibatkan peran aktif manusia (Chang et al., 2009; Gertzen et al., 2008).

Salah satu parameter untuk mengetahui potensi pelepasliaran suatu spesies adalah propagule pressure, yaitu estimasi jumlah individu spesies yang kemungkinan besar dilepasliarkan (Simberloff, 2009) dengan memperhatikan persepsi dan pengetahuan pelaku perdagangan terhadap jenis ikan target (Gertzen et al., 2008). Parameter ini dapat memprediksi potensi introduksi sehingga pencegahannya dapat dilakukan lebih efisien (Gertzen et al., 2008).

Studi ini dilakukan untuk mengetahui sebaran spesies ikan akuatik tawar berbahaya, invasif, dan berpotensi invasif yang diperdagangkan di Yogyakarta dan sekitarnya, dan mengetahui potensi pelepasliarannya melalui perantara manusia berdasarkan karakteristik biologis yang dapat memicu pelepasliarannya dan persepsi pelaku perdagangan terhadap spesies tersebut. Informasi hasil penelitian ini diharapkan dapat digunakan untuk merumuskan langkah-langkah pengendaliannya sebagai bahan masukan penyusunan peraturan dan kebijakan oleh pemerintah.

\section{BAHAN DAN METODE \\ Pemetaan Jenis Ikan Berbahaya/invasif dan Berpotensi Invasif}

Penelitian dilaksanakan pada Mei hingga September 2017 di 46 lokasi di Daerah Istimewa Yogyakarta dan sekitarnya dengan metode penelitian kasus dengan jumlah responden sebanyak 46 orang baik sebagai pemilik kios, pedagang, dan kolektor ikan 
hias. Studi kasus adalah rancangan penelitian yang mencakup suatu objek penelitian yang dilakukan secara intensif dan terperinci dengan berpedoman pada kuesioner dan pengamatan langsung terhadap berbagai komponen yang belum tercakup dalam kuesioner (Nazir, 1988). Metode kerja penelitian merujuk pada Petunjuk Teknis Pemetaan Sebaran Jenis Ikan Bersifat Invasif (BKIPM, 2017) dan studi pemetaan spesies akuatik asing oleh Chang et al. (2009) dan Gertzen et al. (2008) yang telah disesuaikan.

Data primer dikumpulkan melalui inventarisasi jenis spesies akuatik air tawar berbahaya/invasif dan berpotensi invasif apa saja yang tersedia di lokasi responden sesuai dengan lampiran Keputusan Kepala Badan Karantina Ikan, Pengendalian Mutu dan Keamanan Hasil Perikanan Nomor 31/KEP-BKIPM/ 2017 (BKIPM, 2017) termasuk panduan lain tentang jenis ikan invasif, ancaman dan pengendaliannya $($ Haryono et al., 2016)*). Identifikasi spesies akuatik dilakukan melalui laman www.fishbase.org (Froese \& Pauly, 2017). Pengumpulan data primer meliputi wawancara langsung dengan responden dan pengumpulan data transaksi ikan hias.

Data sekunder diperoleh dari sumber informasi berupa studi kepustakaan dan hasil penelitian sebelumnya termasuk data sebaran spesies target di perairan umum. Informasi lokasi responden dikumpulkan dari data hasil pencarian online (Chang et al., 2009) melalui google search dengan keyword "ikan hias", "aquarium", "akuarium", "iwak galak", dan lokasi target kota/kabupaten.

\section{Survei Komoditas Ikan Hias}

Dari seluruh jenis ikan hias yang didata dilakukan identifikasi jenis ikan target dan dihitung persentasenya. Disamping itu dilakukan pendataan terhadap dimilikinya fasilitas pembenihan, rata-rata jumlah ikan terjual per bulan, rata-rata omset penjualan

*) Spesies akuatik berbahaya /invasif adalah jenis ikan tertentu dari luar ekosistem tertentu yang masuk ke dalam ekosistem baru dan membahayakan kelestarian sumber daya ikan, lingkungan, dan manusia. Spesies akuatik berpotensi invasif adalah jenis asing yang cenderung berdampak negatif terhadap kelestarian populasi ikan asli. Berdasarkan karakter biologisnya sifat keinvasifan dapat dicirikan diantaranya: predator, kompetitor, daya reproduksi cepat dan tinggi, pembawa penyakit berbahaya, pemakan segala/ omnivora, pertumbuhannya cepat, kematangan seksual cepat, dapat melakukan hibridisasi dan menurunkan sifat genetiknya, dan berdampak negatif terhadap manusia (Haryono et al., 2016). ikan per bulan, dan ada tidaknya perizinan dibidang perikanan, dan daerah asal ikan. Tingkat mortalitas antar spesies diasumsikan stabil diantara seluruh responden dimana selama survei dilakukan tidak ditemukan laporan kematian massal ikan misal akibat penyakit.

\section{Survei Persepsi Responden Terhadap Spesies Target}

Pengumpulan data responden dilakukan dengan serangkaian pertanyaan tertutup dengan meminimalisir bias melalui topik pertanyaan dari hal yang bersifat umum berangsur-angsur ke pertanyaan yang lebih spesifik. Pertanyaan tersebut diajukan untuk menggali informasi sejauh mana responden mengetahui spesies target dan bahayanya termasuk apakah responden menyadari bahwa tempat usahanya merupakan sumber peredaran, potensi pelepasliaran oleh penjual maupun konsumen dalam kondisi tertentu misalnya tidak segera laku dijual atau pada saat pemeliharaan oleh konsumen akibat karakter biologis ikan misal terlalu agresif, tumbuh lebih besar dari kemampuan konsumen untuk memeliharanya, rentan penyakit, bosan atau alasan lain (Duggan et al., 2006).

Untuk mengetahui tanggungjawab responden diajukan pertanyaan tentang apakah responden mengedukasi konsumen agar tidak melepasliarkan ikan, adakah pelabelan pada setiap jenis ikan, kesediaan responden memilih jenis lain yang tidak bersifat invasif, dan kesediaan bekerja sama dengan berbagai pihak dalam upaya pencegahan penyebaran spesies target. Untuk mengetahui pengaruh lokasi perdagangan (dalam satu kompleks atau individual) dan kepemilikan pembenihan serta interaksi diantara keduanya terhadap jumlah jenis spesies target yang diperdagangkan maka dilakukan uji menggunakan analisa varian dua arah $(\alpha=0,05)$ dengan ulangan sejumlah 6 responden per kelompok. Pengujian dilakukan dengan menggunakan SPSS IBM versi 22 dimana normalitas distribusi data dengan Uji Shapirowilk ( $\alpha=0,05)$ terhadap data responden dengan hasil data telah memenuhi asumsi normalitas baik dalam kategori kepemilikan fasilitas pembenihan ((punya pembenihan ( $\mathrm{df}=12, \mathrm{p}=0,748)$; tidak ada pembenihan $(\mathrm{df}=12, \mathrm{p}=0,080)$ ) dan lokasi ((dalam satu kompleks $(\mathrm{df}=12, \mathrm{p}=0,403$; mandiri $(\mathrm{df}=12, \mathrm{p}$ $=0,961))$. Data juga telah memenuhi asumsi homogenitas baik untuk kategori pembenihan ( $\mathrm{df}=$ $22, p=0,213)$ dan lokasi $(d f=22, p=0,209)$. 


\section{Perhitungan Propagule pressure Total}

Perhitungan propagule pressure total dilakukan berdasarkan hasil survei komoditas ikan hias dan persepsi responden terhadap ikan target dengan menggunakan statistika bayesian sebagaimana ditunjukkan dalam studi oleh Gertzen et al. (2008). Responden dengan data jumlah dan jenis spesies target yang diperdagangkan merefleksikan propagule pressure yang akan dihitung (Rixon et.al., 2005). Total Propagule Pressure dapat dirumuskan dengan:

$T P P=M \cdot P(I) \cdot N \cdot P(R \mid I)$

dimana TPP $=$ Total Propagule Pressure; $\mathrm{M}=$ jumlah pembeli ikan target di lokasi penjualan perbulan; $\mathrm{P}(\mathrm{I})$ probabilitas seseorang memiliki kecenderungan melakukan pelepasliaran karena minim edukasi oleh penjual ikan; $\mathrm{N}=$ rata-rata ikan target yang dimiliki seseorang; $\operatorname{dan} P(R \mid I)=$ probabilitas suatu spesies dilepasliarkan karena dimiliki oleh orang yang berpotensi melakukan hal tersebut.

\section{Perhitungan Propagule pressure Spesies Tertentu}

Propagule pressure spesies tertentu merupakan estimasi jumlah individu invasif yang berpotensi terlepasliarkan per spesies dengan memperhatikan profil ukuran populasi spesies target yang diperdagangkan dan karakteristik biologis yang melekat pada spesies tersebut yang memicu pelepasliaran. Propagule Pressure spesies tertentu dapat dirumuskan sebagaimana mengacu pada Gertzen et al. (2008) yaitu:

$$
\text { PPst }=M \cdot P(I) \cdot N \cdot P(R \mid I) \cdot r_{x} \cdot C \cdot s_{x}
$$

dimana PPst $=$ Propagule Pressure spesies tertentu; data $\mathrm{M}, \mathrm{P}(\mathrm{I}), \mathrm{N}$, dan $\mathrm{P}(\mathrm{R} \mid \mathrm{I})$ sama dengan elemen dalam Propagule Pressure total. $r_{x}=$ tingkat relatif suatu pelepasan spesies tertentu bergantung pada karakter spesifik yang memicu pelepasan; c = faktor koreksi; $s_{x}=$ proporsi relatif dari suatu jenis ikan target tertentu dari seluruh responden dibandingkan dengan stok seluruh ikan target dari seluruh responden dalam waktu tertentu.

Pada umumnya konsumen mulai kesulitan memelihara ikan yang lebih agresif dan pertumbuhannya terlalu besar (Gertzen et al., 2008). Variabel $r_{x}$ menggambarkan tingkat probabilitas pelepasan, dihitung dari proporsi suatu ikan yang berpotensi dilepas karena alasan tertentu, yaitu alasan dasar ( $T$ ) seperti rentan penyakit, reproduksi tinggi, bosan, dll., atau kombinasi diantara alasan tersebut, dan alasan agresifitas ikan (Ta), ukuran terlalu besar (Ts), dan kombinasi agresif dan ukuran besar (Tas). Sehingga $r_{x}$ dapat dirumuskan: $r=T / T$, merupakan tingkat pelepasan dasar relatif (untuk alasan dasar - non agresif dan bukan karena ukuran besar); $r_{a}=(T+T a) / T$, tingkat pelepasan relatif untuk spesies tertentu berdasarkan alasan agresif namun tidak karena ukuran; $r_{s}=(T+T s) / T$, tingkat pelepasan relatif untuk spesies tertentu berdasarkan alasan ukuran namun tidak agresif; $r_{a s}=(T+T a+T s) / T$, tingkat pelepasan relatif untuk spesies tertentu berdasarkan alasan ukuran besar dan agresif. Untuk mengetahui tingkat pelepasan yang sesungguhnya maka diperlukan faktor koreksi (c) dengan rumus:

$$
C=\frac{1}{(\text { F.r })+(\text { Fas.ras })+(\text { Fs.rs })+(\text { Fa.ra })}
$$

Faktor koreksi mencakup elemen tingkat pelepasan relatif akibat karakter biologi yang tidak diinginkan dan jumlah ikan total terjual per kategori karakter yang tidak diinginkan (F, Fa, Fs, Fas).

\section{HASIL DAN BAHASAN Hasil}

\section{Sebaran Spesies Target dan Survei Komoditas Ikan Hias}

Inventarisasi jenis ikan di 46 lokasi perdagangan ikan hias air tawar berhasil mengidentifikasi 168 spesies di mana rata-rata setiap kios memperdagangkan 24 jenis ikan. Spesies target yang terpetakan disajikan dalam lampiran 1.

Sebanyak $97 \%$ dari total 46 responden memperdagangkan jenis ikan target. Per lokasi ratarata memperdagangkan spesies target hingga 35\% dari total jenis ikan yang ada. Fasilitas pembenihan dimiliki oleh $46 \%$ dari seluruh responden, namun hanya $15 \%$ saja yang memiliki perijinan. Sebanyak $37 \%$ responden memproduksi sendiri jenis ikan target. Responden yang melakukan lalu lintas ikan antar area sebanyak $28 \%$. Ditemukan ikan berpotensi invasif seperti louhan yang diimpor dari Thailand atau jenis ikan asing lain masuk melalui Jakarta dan didistribusikan ke daerah lain.

Adapun $75 \%$ responden mendapatkan pasokan produk dari Jawa Timur khususnya Tulungagung. Jenis ikan berbahaya untuk manusia seperti piranha dan alligator gar dipasok dari daerah tersebut. Jumlah ikan hias yang beredar termasuk ikan dari kota besar lain di Pulau Jawa via darat untuk kemudian dilalulintaskan ke luar Jawa melalui Bandara Internasional Adi Sucipto. Persentase rata-rata omset 
penjualan spesies target per bulan mencapai $37 \%$. Diantara seluruh ikan target yang ditemukan tidak ada yang memerlukan pengaturan suhu media pemeliharaan khusus diluar lingkungan tropis.

\section{Persepsi Pelaku Perdagangan Ikan Hias Terhadap Spesies Target}

Pengetahuan tentang spesies target oleh responden cukup rendah yaitu sebesar $24 \%$. Pengetahuan atas bahaya spesies target mencapai $30 \%(14 / 46)$. Hanya $7 \%$ dari seluruh responden yang sadar bahwa tempat usahanya menjadi sumber peredaran. Responden yang memiliki fasilitas pembenihan lebih banyak yang mengetahui tentang spesies target dibandingkan yang tidak memiliki pembenihan, yaitu $43 \%$ (9/21) dibanding $8 \%(2 / 25)$. Pengetahuan bahaya spesies target oleh responden dengan pembenihan mencapai $52 \%$ dibandingkan $12 \%$ oleh responden tanpa pembenihan. Hal ini tidak berarti bahwa responden yang memiliki pembenihan lebih sadar karena hasil survei menunjukkan $76 \%$ responden tersebut memproduksi sendiri spesies target. Persentase spesies target yang diperdagangkan oleh responden dengan pembenihan lebih tinggi yaitu $45 \%$ dibandingkan $27 \%$ oleh responden tanpapembenihan. Sebanyak $57 \%$ responden dengan pembenihan melakukan lalu lintas ikan hias antar area dan hanya $14 \%$ yang menyadari bahwa usahanya merupakan pusat peredaran jenis ikan target.

Secara umum hanya $17 \%$ dari seluruh responden yang melakukan pelepasliaran. Sayangnya untuk responden yang memiliki fasilitas pembenihan cenderung lebih tidak bertanggungjawab dimana 33 \%-nya akan melakukan pelepasliaran dibandingkan responden yang hanya memiliki fasilitas penjualan. Persepsi responden terhadap pentingnya edukasi kepada konsumen tentang spesies target cukup rendah yaitu hanya $24 \%$ dari seluruh pemilik usaha yang menganjurkan kepada konsumennya supaya tidak melepasliarkan ikan. Pemasangan label nama ikan di fasilitas penjualan hanya ditemukan di 7 lokasi. Responden yang memiliki pembenihan hanya $33 \%$ saja yang mengedukasi konsumen, lebih tinggi dua kali lipatnya dari responden tanpa fasilitas tersebut walaupun pelabelan nama ikan pada responden terakhir lebih tinggi persentasenya.

Terlepas dari persepsi responden terhadap ikan invasif yang secara umum lebih cenderung negatif, hampir seluruh responden (98\%) bersedia bekerja sama dengan otoritas kompeten dan pemangku kepentingan lain untuk mencegah penyebaran spesies target. Namun begitu, setiap responden memiliki persepsi sendiri tentang bentuk pencegahan apa yang tidak mengganggu bisnis mereka. Sebab rata-rata omset penjualan ikan invasif mereka tidak kurang dari $37 \%$ omset total. Oleh karena itu hanya $17 \%$ saja yang bersedia melakukan substitusi jenis ikan invasif yang dijual maupun yang diproduksinya dengan jenis lain non invasif.

Hasil analisa varian dua arah $(\alpha=0,05)$ memperlihatkan bahwa responden yang berlokasi secara berkelompok dan mandiri memperdagangkan jenis ikan invasif/potensi invasif dalam jumlah yang tidak berbeda baik yang memilliki fasilitas pembenihan maupun tidak $(F=0,868 ; d f=1,20 ; p=0,363)$. Ratarata jumlah jenis ikan invasif yang dijual responden yang memiliki fasilitas pembenihan tidak berbeda dengan responden yang tidak memiliki fasilitas pembenihan $(F=0,96 ; d f=1,20 ; p=0,759)$. Sebaliknya responden yang berlokasi tidak dalam 1 kompleks memperdagangkan jenis ikan target lebih bervariasi dibandingkan responden yang berjualan di dalam satu kompleks ( $F=6,174 ; d f=1,20 ; p=0,022)$ dimana rata-rata jumlah spesies target pada lokasi mandiri sebanyak 10 jenis ikan.

\section{Propagule pressure Total dan Propagule pressure per Spesies}

Total seluruh stok dari seluruh jenis ikan yang diperdagangkan sebesar 256.980 ekor per bulan dimana stok ikan target tercatat sejumlah 53.637 termasuk jenis yang tergolong transgenik dan memiliki riwayat invasif global walaupun belum masuk dalam peraturan perundangan. Jumlah pengunjung lokasi penjualan per bulan yang diperkirakan membeli spesies target sebanyak 6.596 pelanggan (M). Hasil survei menunjukkan bahwa persentase atau probabilitas pelepasliaran karena tidak adanya edukasi tentang spesies invasif dan bahayanya kepada konsumen adalah sebesar $76 \%$ atau 0,76 ( $\mathrm{P}(\mathrm{I}))$. Adapun $\mathrm{P}(\mathrm{R} \mid \mathrm{I})$ atau probablitias ikan yang dilepas oleh orang yang cenderung melakukan pelepasliaran sebesar 0,17 . Estimasi rata-rata ikan invasif yang dimiliki konsumen diperoleh dari data stok ikan invasif seluruh responden dan estimasi jumlah pelanggan. yaitu 8 ekor per orang $(\mathrm{N})$. Keseluruhan elemen perhitungan diatas dikalkulasikan untuk mendapat nilai propagule pressure total sebesar 6.818 ekor ikan target yang dprediksikan terlepasliarkan.

Propagule pressure setiap spesies diperoleh dengan mengkalkulasikan propagule pressure total dengan elemen karakter biologi dan profil populasi masing-masing spesies target yang beredar di seluruh responden. Berdasarkan hasil interview diperoleh ratarata persentase karakteristik ikan hias yang diperdagangkan seluruh responden yang dapat 
memicu pelepasliaran untuk ikan yang cenderung agresif sebesar 0,08 (Ta); tumbuh terlalu besar sebesar 0,06 (Ts); dan alasan mendasar seperti rentan penyakit, reproduksi tinggi, bosan, dll. sebesar 0,86 (T). Berdasarkan data proporsi tersebut maka diperoleh tingkat probablitas pelepasan akibat karakter yang tidak diinginkan yaitu $r=1 . r_{a}=$ 1,093023. $r_{s}=1,0697674 . r_{\text {as }}=1,162791$. Adapun $S x$ atau Tingkat Stok Ikan Relatif per Spesies dari seluruh responden disajikan dalam Tabel 1. Agar perhitungan propagule pressure per spesies untuk seluruh jenis ikan target sesuai dengan propagule pressure total maka diperlukan faktor koreksi (c) yang mencakup elemen tingkat probabilitas pelepasan berdasar karakter biologis yang tidak diinginkan dan tingkat penjualan relatif ikan target berdasarkan karakter tersebut masing-masing ( $\mathrm{Fx}$ ) dengan nilai Fa atau total penjualan relatif untuk karakter agresif $=0,185264$; Fs untuk karakter ukuran $=0,013088$; Fas untuk karakter kombinasi agresif dan ukuran $=0,067081$; dan $\mathrm{F}$ untuk karakter dasar $=0,734568$. Sehingga diperoleh nilai faktor koreksi (c) =0,971754.

\section{Bahasan}

Hasil studi ini menunjukkan bahwa Yogyakarta dan sekitarnya rentan terhadap peredaran spesies akuatik berbahaya, invasif, dan berpotensi invasif. Apalagi survei menunjukkan bahwa lebih dari 3/4 responden tidak mengetahui tentang spesies target dan bahayanya bagi ekosistem dan kesehatan manusia disamping minimnya ijin usaha mereka sehingga pengawasan otoritas kompeten tidak optimal. Minimnya edukasi kepada konsumen dan rendahnya persepsi positif pelaku perdagangan dapat memicu pelepasliaran. Rata-rata responden yang mengetahui ikan invasif adalah sebatas sebagai ikan galak/ karnivora. Banyak yang tidak mengetahui bahwa ikan seperti guppy, louhan, plati pedang, gabus, dan toman memiliki potensi invasif berdasarkan Keputusan Kepala BKIPM Nomor 31/KEP-BKIPM/2017.

Sebaliknya, pemberlakuan status potensi invasif kepada jenis-jenis ikan diatas tentu saja tidak akan terlepas dari perdebatan apalagi diantaranya merupakan jenis ikan lokal seperti Channa striata dan C. micropeltes. Beberapa jenis ikan berpotensi invasif lain yaitu Cyprinus carpio, Oreochromis niloticus, dan Colossoma macropomum merupakan jenis asing dan menjadi tumpuan utama produksi perikanan budidaya oleh masyarakat. Tentu akan sulit diterima apabila spesies tersebut diperketat peredarannya. Fenomena yang sama hampir terjadi dibanyak negara sebagaimana diuraikan oleh Vitule et al. (2009) dan Casal (2006) di mana introduksi spesies akuatik invasif tidak terbendung akibat kegiatan budidaya dan pemancingan. Pada tingkat global setengah dari introduksi ribuan jenis ikan untuk kegiatan budidaya diketahui telah tersebar dan berhasil membentuk populasi baru di perairan umum (Casal, 2006) dan lebih dari $50 \%$ jenis ikan berbahaya yang dilarang masuk ke Indonesia telah hadir di perairan umum maupun diperdagangkan (Haryono et al., 2016). Belum optimalnya peraturan yang ada menjadi pemicu konflik antara pemerhati lingkungan dan pemangku kepentingan produsen perikanan budidaya (Vitule et al., 2009).

Adapun dampak tersebarnya jenis-jenis ikan target adalah kemampuan mengubah struktur komunitas lokal (Cardona et al., 2008). mengganggu kelimpahan zooplankton. meningkatkan kekeruhan perairan dan kelimpahan mikroalga secara tidak wajar dan berpotensi hama seperti jenis Tilapia (Fishbase, n.d.; Haryono et al., 2016), introduksi penyakit baru (Crowl et al., 2008; Vitule et al., 2009), hibridisasi dengan spesies lokal seperti pada kasus ikan guppy (Sievers et al., 2012), dan menimbulkan kerugian di berbagai negara seperti pada ikan mas (Casal, 2006).

Terpetakannya spesies akuatik yang belum tertera dalam perundangan, yaitu Trachemys scripta elegans yang merupakan salah satu dari 100 spesies paling invasif di dunia (Global Invasive Species Database, 2017). Akibat ketidaktahuan masyarakat, reptil akuatik ini dilepasliarkan di Sungai Tempuran Wonogiri secara massal dengan dalih mengatasi sedimentasi sungai (Wismabrata, 2015). Disamping itu lokasi perdagangan ikan hias juga diramaikan dengan jenis ikan transgenik yaitu Red Neon Zebra/Pink Zebra (Danio rerio). Ikan ini diproduksi di Amerika Serikat dengan warna merah/pink dan warna lain yang tidak alami (Cottle, 2017) yang mana warna asli ikan ini keperakan (Cortemeglia \& Beitinger, 2006). Ikan transgenik ini juga dikembangkan di Singapura (Davies, 2014). diduga tersebar melalui importasi ke Indonesia dan dikembangbiakkan didalam negeri. Dampak ikan Red Neon Zebra terhadap ekosistem belum diketahui sehingga dapat dikategorikan beresiko tinggi (Vitule et al., 2009).

Dalam studi ini, propagule pressure keseluruhan jenis ikan target yang beredar dalam perdagangan ikan hias mencapai 6.818 individu. Nilai tersebut dapat diartikan bahwa dari total stok ikan hias yang terpetakan, sebesar 6.818 individu berpotensi terlepasliarkan dengan vektor manusia akibat persepsinya atas spesies target yang tidak teredukasi dengan baik. Terdapat 8 spesies target memiliki propagule pressure lebih dari 100 individu. Propagule pressure melebihi angka 100 maka apabila terlepas diperairan umum cukup untuk membentuk populasi 
baru (Moyle \& Marchetti, 2006). Munculnya populasi baru di habitat baru ditentukan oleh kecukupan jumlah individu yang diintroduksi dan frekuensi kejadian masuknya spesies tersebut di habitat baru (Ricciardi et al., 2011; Sakai et al., 2001). Diketahui bahwa beberapa spesies yang terpetakan memiliki relung masing-masing di berbagai perairan umum di Yogyakarta (Djasmani \& Djumanto, 2014; Trijoko \& Pranoto, 2006; Zaenudin, 2013). Jika terjadi pelepasliaran berulang maka dimungkinkan timbulnya dampak ekologis negatif (Lockwood et al., 2005; Ricciardi et al., 2011).

Berdasarkan hasil studi ini diketahui bahwa maraknya peredaran jenis ikan target sangat dipengaruhi oleh belum optimalnya kelengkapan peraturan perundangan-undangan yang ada, rendahnya tingkat pengetahuan masyarakat serta minimnya pengendalian di luar pintu pemasukan dan pengeluaran. Oleh karena itu, upaya edukasi terhadap masyarakat memegang peranan yang signifikan disamping diperlukan penguatan regulasi. Apalagi UU Nomor 45 Tahun 2009 Tentang Perubahan Atas UU Nomor 31 Tahun 2004 tentang Perikanan memuat sanksi pidana cukup berat dalam peredaran jenis ikan berbahaya (KKP, 2009). Upaya peningkatan pengetahuan masyarakat di Yogyakarta juga perlu difokuskan kepada pelaku usaha yang memiliki lokasi penjualan tidak berada dalam satu kompleks perdagangan satwa karena lebih beragamnya spesies target yang dijual.

\section{KESIMPULAN}

Dari analisis kondisi introduksi, ikan invasif, ikan potensial invasif dan perhitungan propagule pressure menunjukkan maraknya peredaran dan tingginya potensi pelepasliaran spesies target dipengaruhi oleh minimnya peran serta masyarakat dalam upaya pencegahan peredarannya. Hal ini dapat diketahui dari seluruh pertanyaan untuk mengetahui pengetahuan, kesadaran, dan tanggungjawab responden sebanyak $75 \%$ merupakan respon negatif. Oleh karena itu upaya pengendalian dapat dilakukan dengan target utama pencegahan pelepasliaran melalui edukasi ke instansi pemerintah lokal dan masyarakat serta pengetatan lalu lintas antar area termasuk antar area tidak bebas. Upaya hukum lebih tegas diluar tempat pemasukan dan pengeluaran dapat menjadi target jangka panjang apabila usaha pembinaan dan pemberdayaan masyarakat telah dilaksanakan secara optimal.

\section{PERSANTUNAN}

Penulis menyampaikan terimakasih kepada Kepala Stasiun KIPM Kelas I Yogyakarta Bapak Suprayogi, S.Pi., M.P. atas dukungannya dalam studi ini serta Bapak Dr. Ir. Djumanto, M.Sc dan Drs. N Probosunu, M.Si atas bimbingannya selama pelaksanaan studi ini.

\section{DAFTAR PUSTAKA}

Bagjariani, A. (2013). Analisis risiko produksi pembenihan ikan bawal air tawar (Colossoma macropomum) (Studi Kasus pada Usaha Perikanan H. Ijam di Desa Cikupa, Kecamatan Tenjolaya, Kabupaten Bogor) [Skripsi]. Retrieved from http://repository.ipb.ac.id/handle/123456789/ 63898.

BKIPM. (2017). Keputusan Kepala Badan Karantina Ikan, Pengendalian Mutu dan Keamanan Hasil Perikanan Nomor 31/KEP-BKIPM/2017 Tentang Petunjuk Teknis Pemetaan Sebaran Jenis Ikan Bersifat Invasif. Retrieved from http:// www.bkipm.kkp.go.id/bkipmnew/public/files/ regulasi / $31 \% 20 \mathrm{kep} \% 20 \mathrm{bkipm}$ $\% 202017 \% 20$ Petunjuk\%20 Teknis \% 20Pemetaan\%20Sebaran\% 20Jenis\%20lkan\% 20Bersifat\%20In vasif.pdf.

Cardona, L., Hereu, B., \& Torras, X. (2008). Juvenile bottlenecks and salinity shape grey mullet assemblages in Mediterranean estuaries. Estuarine, Coastal and Shelf Science, 77(4), 623-632. doi: 10.1016/j.ecss.2007.10.018.

Casal, C. M. V. (2006). Global documentation of fish introductions: the growing crisis and recommendations for action. Biological Invasions, 8(1), 311. doi: 10.1007/s10530-005-0231-3.

Chang, A. L., Grossman, J. D., Spezio, T. S., Weiskel, H. W., Blum, J. C., Burt, J. W., . . Grosholz, E. D. (2009). Tackling aquatic invasions: risks and opportunities for the aquarium fish industry. Biological Invasions, 11(4), 773-785. doi: 10.1007/ s10530-008-9292-4

Cortemeglia, C., \& Beitinger, T. L. (2006). Susceptibility of transgenic and wildtype zebra danios, Danio rerio, to predation. Environmental Biology of Fishes, 76(1), 93-100. doi: 10.1007/s10641-006-9011-x.

Cottle, P. (2017). Danio Rerio. Retrieved 20 September, 2017, from http://www.danios.info/fish/ rerio.aspx. 
Crowl, T. A., Crist, T. O., Parmenter, R. R., Belovsky, G., \& Lugo, A. E. (2008). The spread of invasive species and infectious disease as drivers of ecosystem change. Frontiers in Ecology and the Environment, 6(5), 238-246. doi: 10.1890/070151.

Davies, G. (2014). Searching for GloFish®: aesthetics, ethics, and encounters with the neon baroque. Environment and Planning A, 46(11), 2604-2621.

Dinisari, M. C. (2016). Gerpari 2017 Akan Salurkan 500 Paket Pakan Ikan. Retrieved 28 maret, 2017, from http://industri.bisnis.com/read/20160927/99/ 587167/gerpari-2017-akan-salurkan-500-paketpakan-ikan.

Djasmani, S. S., \& Djumanto, D. (2014). Komposisi Ikan Hasil Tangkapan Jaring Insang Pada Berbagai Shortening di Waduk Sermo. Jurnal Perikanan Universitas Gadjah Mada, 16(1), 35-42.

DJPB-KKP. (2017). Peraturan Direktur Jenderal Perikanan Budidaya Nomor 29 /PER-DJPB/2017 Tentang Petunjuk Teknis Bantuan Benih Ikan Oleh Unit Pelaksana Teknis Daerah Provinsi Dan Unit Pelaksana Teknis Lingkup Direktorat Jenderal Perikanan Budidaya Jakarta: DIrektorat Jenderal Perikanan Budidaya - Kementerian Kelautan dan Perikanan. Retrieved from https:// www.djpb.kkp.go.id/index.php/arsip/file/490/ petunjuk-teknis-bantuan-benih-oleh-uptd-dan-uptlingkup-djpb.pdf/.

Duggan, I. C., Rixon, C. A. M., \& Maclsaac, H. J. (2006). Popularity and propagule pressure: determinants of introduction and establishment of aquarium fish. Biol. Invasions, 8, 377-382. doi: 10.1007/s10530-004-2310-2.

Fishbase. (n.d.). Oreochromis niloticus (Linnaeus, 1758). Retrieved 02 October 2017, from http:// www.fishbase.org/summary/2.

Fowler, A. J., Lodge, D. M., \& Hsia, J. F. (2007). Failure of the Lacey Act to protect US ecosystems against animal invasions. Frontiers in Ecology and the Environment, 5(7), 353-359. doi: 10.1890/15409295(2007)5[353:FOTLAT]2.0.CO;2.

Froese, R., \& Pauly, D. (2017). FishBase. World Wide Web electronic publication. version (06/2017). Retrieved 15 September, 2017, from http:// www.fishbase.org/.

García Berthou, E. (2007). The characteristics of invasive fishes: what has been learned so far? Jour- nal of Fish Biology, 71(sd), 33-55. doi: 10.1111/ j.1095-8649.2007.01668.x.

Gertzen, E., Familiar, O., \& Leung, B. (2008). Quantifying invasion pathways: fish introductions from the aquarium trade. Canadian Journal of Fisheries and Aquatic Sciences, 65(7), 1265-1273. doi: 10.1139/F08-056.

Global Invasive Species Database. (2017). Trachemys scripta elegans. Retrieved 15 October, 2017, from http://www.iucngisd.org/gisd/search.php.

Gozlan, R. E. (2008). Introduction of non native freshwater fish: is it all bad? Fish and Fisheries, 9(1), 106-115. doi: 10.1111/j.1467-2979.2007.00267.x.

Gurevitch, J., \& Padilla, D. K. (2004). Are invasive species a major cause of extinctions? Trends in Ecology \& Evolution, 19(9), 470-474. doi: 10.1016/ j.tree.2004.07.005.

Haryono, Wahyudewantoro, G., Walidi, W., Tani, D. D., Anggraeni, Y., Arta, A. P., . . . Supardan, A. (2016). Jenis Ikan Invasif, Ancaman dan Pengendaliannya. Jakarta: Bidang Keamanan Hayati Ikan, Pusat Karantina dan Keamanan Hayati Ikan, Kementerian Kelautan dan Perikanan, Bekerjasama dengan Pusat Penelitian Biologi-LIPI.

Haynes, G. D., Gongora, J., Gilligan, D. M., Grewe, P., Moran, C., \& Nicholas, F. W. (2012). Cryptic hybridization and introgression between invasive Cyprinid species Cyprinus carpio and Carassius auratus in Australia: implications for invasive species management. Animal Conservation, 15(1), 8394. doi: 10.1111/j.1469-1795.2011.00490.x.

Hulme, P. E. (2009). Trade, transport and trouble: managing invasive species pathways in an era of globalization. Journal of applied ecology, 46(1), 1018. doi: 10.1111/j.1365-2664.2008.01600.x.

Ishikawa, T., \& Tachihara, K. (2014). Introduction history of non-native freshwater fish in Okinawa-jima Island: ornamental aquarium fish pose the greatest risk for future invasions. Ichthyological research, 61(1), 17-26. doi: 10.1007/s10228-0130367-6.

KKP. (2009). Undang-Undang Republik Indonesia Nomor 45 Tahun 2009 Tentang Perubahan Atas Undang-Undang Nomor 31 Tahun 2004 Tentang Perikanan. Retrieved from http:// pelayanan.jakarta.go.id/download/regulasi/ 
undang-undang-nomor-45-tahun-2009-tentangperikanan.pdf.

KKP. (2014). Peraturan Menteri Kelautan dan Perikanan Republik Indonesia Nomor 41/PERMEN$\mathrm{KP} / 2014$ tentang Larangan Pemasukan Jenis Ikan Berbahaya Dari Luar Negeri Ke Dalam Wilayah Negara Republik Indonesia. Jakarta: Kementerian Kelautan dan Perikanan Retrieved from http:// www.bkipm.kkp.go.id/bkipmnew/public/files/ regulasi/41-permen-kp-2014-ttg-laranganpemasukan-jenis-ikan-berbahaya.pdf.

Kolar, C. (2004). Risk assessment and screening for potentially invasive fishes. New Zealand Journal of Marine and Freshwater Research, 38(3), 391397. doi: 10.1080/00288330.2004.9517247.

Kolar, C. S., \& Lodge, D. M. (2001). Progress in invasion biology: predicting invaders. Trends in Ecology \& Evolution, 16(4), 199-204. doi: 10.1016/ S0169-5347(01)02101-2.

Kusrini, E., \& Priyadi, A. (2010). Fenotip Generasi Pertama dari Hasil Hibridisasi Antara Tige Catfish (Pseudoplatystoma fasciatum) Ddengan Redtail Catfish (Phractocephalus hemioliopterus). Paper presented at the Prosiding FORUM INOVASI TEKNOLOGIAKUAKULTUR.

Lockwood, J. L., Cassey, P., \& Blackburn, T. (2005). The role of propagule pressure in explaining species invasions. Trends in Ecology \& Evolution, 20(5), 223-228. doi: 10.1016/j.tree.2005.02.004.

Moyle, P. B., \& Marchetti, M. P. (2006). Predicting invasion success: freshwater fishes in California as a model. AIBS Bulletin, 56(6), 515-524. doi: 10.1641/0006-3568(2006)56[515:PISFFI]2.0.CO;2.

Naylor, R. L., Williams, S. L., \& Strong, D. R. (2001). Aquaculture-A gateway for exotic species. Science, 294(5547), 1655-1656. doi: 10.1126/science. 1064875 .

Nazir, M. (1988). Metode penelitian (p. 66). Ghalia Indonesia, Jakarta.

Padilla, D. K., \& Williams, S. L. (2004). Beyond ballast water: aquarium and ornamental trades as sources of invasive species in aquatic ecosystems. Frontiers in Ecology and the Environment, 2(3), 131-138. doi: 10.1890/15409295(2004)002[0131:BBWAAO]2.0.CO;2.
Ricciardi, A., Jones, L. A., Kestrup, Å. M., \& Ward, J. M. (2011). Expanding the propagule pressure concept to understand the impact of biological invasions. Fifty years of invasion ecology: the legacy of Charles Elton, 225-235. doi: 10.1002/ 9781444329988.ch17.

Ricciardi, A., \& Rasmussen, J. B. (1998). Predicting the identity and impact of future biological invaders: a priority for aquatic resource management. Canadian Journal of Fisheries and Aquatic Sciences, 55(7), 1759-1765. doi: 10.1139/F10-002.

Rixon, C. A. M., Duggan, A. C., Bergeron, N. M. N., Ricciardi, A., \& Maclsaac, H. J. (2005). Invasion risks posed by the aquarium trade and live fish markets on the Laurentian Great Lakes. Biodivers.Conserv., 14, 1365-1381. doi: 10.1007/ s10531-004-9663-9.

Sakai, A. K., Allendorf, F. W., Holt, J. S., Lodge, D. M., Molofsky, J., With, K. A., . . . Ellstrand, N. C. (2001). The population biology of invasive species. Annual review of ecology and systematics, 32(1), 305-332. doi: 10.1146/ annurev.ecolsys.32.081501.114037.

Sievers, C., Willing, E. M., Hoffmann, M., Dreyer, C., Ramnarine, I., \& Magurran, A. (2012). Reasons for the invasive success of a guppy (Poecilia reticulata) population in Trinidad. PloS one, 7(5), e38404. doi: 10.1371/journal.pone.0038404.

Simberloff, D. (2009). The role of propagule pressure in biological invasions. Annual Review of Ecology, Evolution, and Systematics, 40, 81-102. doi: 10.1146/annurev.ecolsys.110308.120304.

Trijoko, \& Pranoto, F. S. (2006). Keanekaragaman Jenis Ikan di Sepanjang Aliran Sungai Opak Daerah Istimewa Yogyakarta. Paper presented at the Prosiding Seminar Nasional Ikan IV, Jatiluhur.

Turkmen, G. \& Karadal, O. (2012). The survey of the imported freshwater decapod species via the ornamental aquarium trade in Turkey. Journal of Animal and Veterinary Advances, 11(15), 28242827.

Vitule, J. R. S., Freire, C. A., \& Simberloff, D. (2009). Introduction of non native freshwater fish can certainly be bad. Fish and Fisheries, 10(1), 98-108. doi: 10.1111/j.1467-2979.2008.00312.x. 
Wismabrata, M. (2015). Warga Desa Lepas 1.000 Kura-kura dan 20.000 lkan ke Sungai Tempuran. from http://regional.kompas.com/read/2015/11/11/ 23222361/Warga.Desa.Lepas.1.000.Kurakura.dan.20.000.Ikan.ke.Sungai.Tempuran.

Zaenudin, A. (2013). Keanekaragaman dan Kelimpahan Ikan di Daerah Hulu dan Tengah Sungai Gajahwong Yogyakarta. (S1 Skripsi), Universitas Islam Negeri Sunan Kalijaga, Yogyakarta. Retrieved from http://digilib.uin-suka.ac.id/12253.
Zambrano, L., Martinez-Meyer, E., Menezes, N., \& Peterson, A. T. (2006). Invasive potential of common carp (Cyprinus carpio) and Nile tilapia (Oreochromis niloticus) in American freshwater systems. Canadian Journal of Fisheries and Aquatic Sciences, 63(9), 1903-1910. doi: 10.1139/ f06-088. 


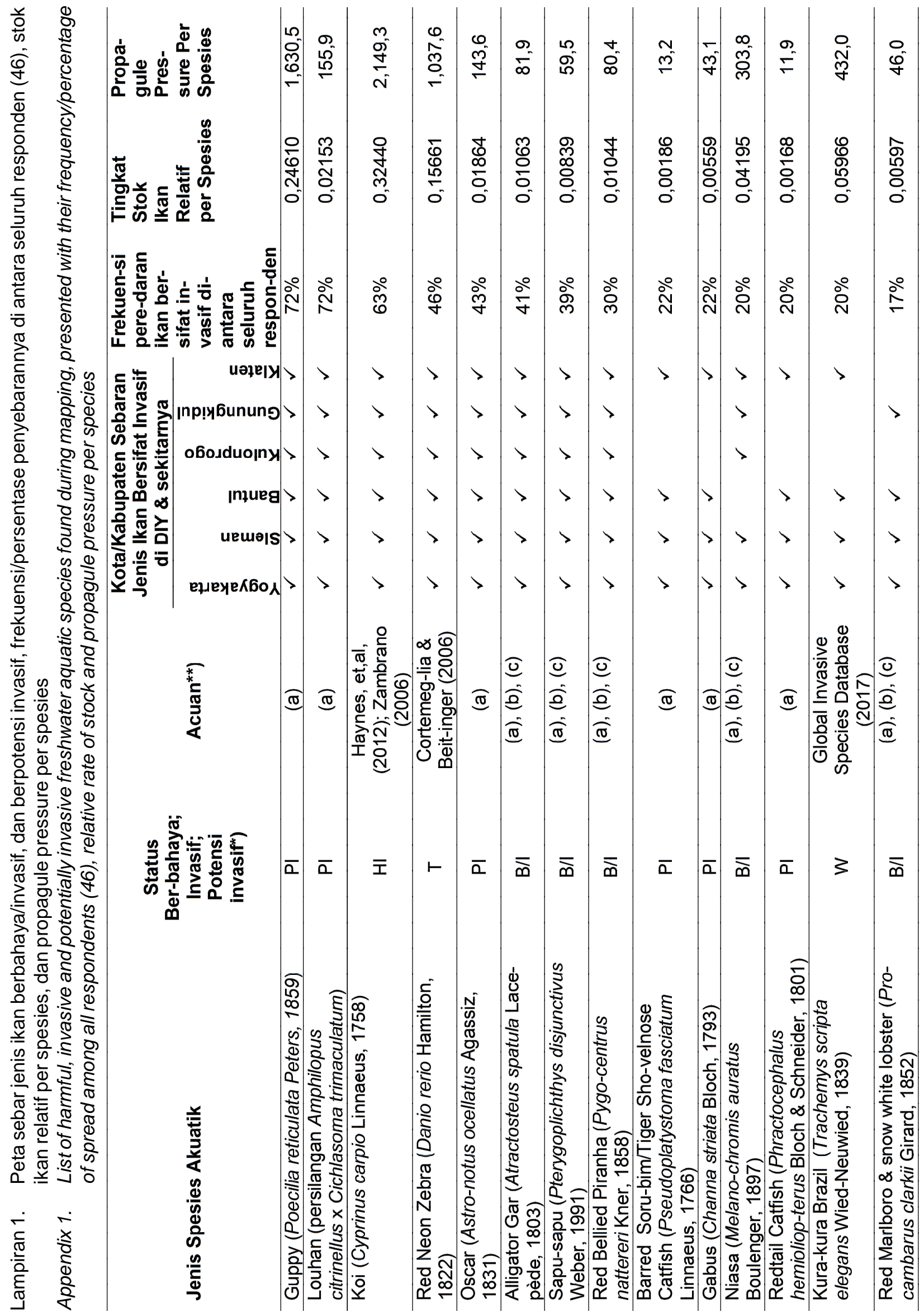




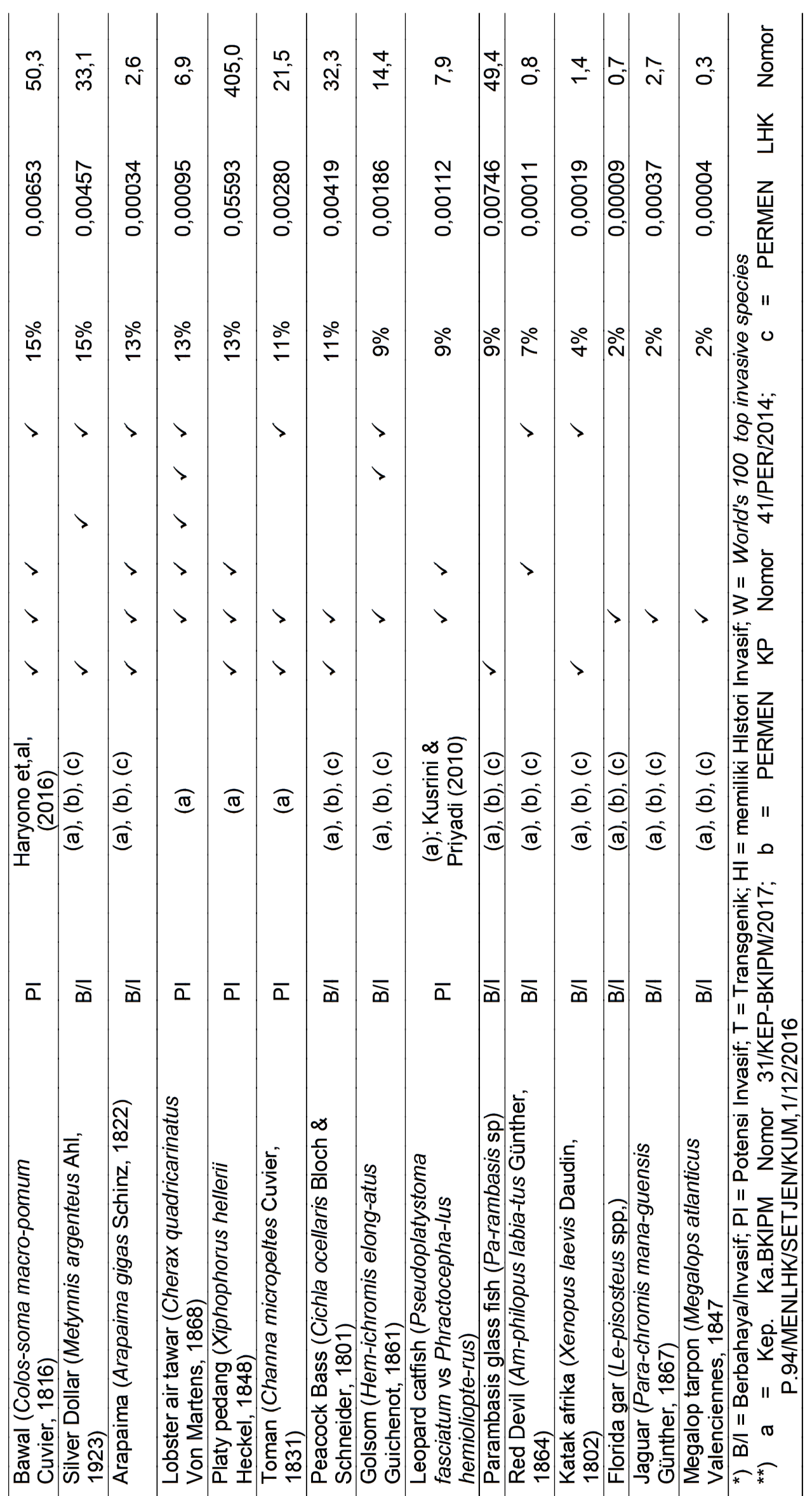

